\title{
Occupational Stress and Anger: Mediating Effects of Resiliency in First Responders
}

\author{
Jessie N. Doyle ${ }^{1}$ (] $\cdot$ Mary Ann Campbell ${ }^{2}$. Lena Gryshchuk ${ }^{1}$
}

Accepted: 19 January 2021 / Published online: 4 February 2021

(c) Society for Police and Criminal Psychology 2021

\begin{abstract}
First responders experience substantial stress due to the nature of their work (Carleton et al. 2017). Occupational stress (OS) results from a myriad of employment conditions (e.g., ambiguous work expectations, unreasonable workload; Osipow 1998). OS can lead to maladaptive anger, which negatively impacts personal well-being and work performance (Velichkovsky 2009). In contrast, resilience to demanding working conditions is associated with lower state and trait anger (Wilson et al. 2001); thus, resilience may serve a protective 'buffer' role against anger in the face of stress. Thus, we hypothesized that resiliency would mediate relations between dimensions of OS and anger. The current study included 201 first responders $\left(\right.$ male $=77.6 \% ; M_{\text {age }}=43.73$ years $(S D=10.97)$; police officers $\left.=64.2 \%\right)$ who completed measures of OS (OSI-R; Osipow 1998), Anger (DSM-5 CC Anger; APA 2013), and Resiliency (CD-RISC; Connor and Davidson 2003). Results indicated that resiliency mediated relations between five components of OS and anger: Role Overload $(p<.001)$; Insufficiency $(p<.001)$; Role Boundary $(p<.001)$; Role Ambiguity $(p<.001)$; and Role Responsibility $(p<.001)$. Results support the importance of resiliency-enhancing interventions to offset the experience of anger when confronted with occupational stress in first responders.
\end{abstract}

Keywords Police employees $\cdot$ First responders $\cdot$ Occupational stress $\cdot$ Anger $\cdot$ Resiliency

\section{Introduction}

First responders, including police officers, firefighters, and dispatch operators, experience substantial stress as a result of their occupation (Carleton et al. 2017). Frequent exposure to life-threatening and potentially traumatic circumstances result in myriad negative mental health reactions in first responders, including acute stress, substance abuse, and major depression (Benedek et al. 2007). Vicarious traumatization, burnout, and compassion fatigue are among some of the other repercussions of first responders' line of work (Daas-Brailsford 2010; Figley 1995), as well as elevated risk for suicide (Stanley et al. 2016). In a Canadian sample of public service personnel (including firefighters,

Jessie N. Doyle

jn.doyle@unb.ca

1 Department of Psychology, University of New Brunswick, E3B 5A3 Fredericton, New Brunswick, Canada

2 Department of Psychology \& Centre for Criminal Justice Studies, University of New Brunswick, E2L 4L5 Saint John, New Brunswick, Canada police officers, paramedics), Carleton et al. (2017) found that depending on the specific occupation, 36.7 to $50.4 \%$ of participants screened for a mental disorder. Indeed, 23.2\% of Carleton et al.'s (2017) sample met criteria for post-traumatic stress disorder (PTSD) based on self-report measures, a figure that echoes prevalence ranging between 8 and 32\% in an American sample of first responders (Kleim and Westphal 2011) and exceeds that which is found in the general population (i.e., 4\%; Kessler et al. 2003, 2005).

When research has investigated occupational stress (OS) within first responder populations, it typically does so in terms of acute, traumatic, and critical incidents (e.g., Benedek et al. 2007; Fridell and Binder 1992; Holloway and Fullerton 1994). Everyday occupational stressors experienced by first responders regarding organizational and interpersonal components, and their influence on mental health, have been largely disregarded. Research that has acknowledged the organizational and interpersonal components of OS (vs. critical incidents) has focused on police officers (Brown et al. 1999; Kop et al. 1999; Paton et al. 2009; van der Velden et al. 2013). For example, Brown et al. (1999) conceptualized organizational and 
interpersonal-related OS as routine, fairly high-frequency incidents that are predictive of general psychological distress in officers. Liberman et al. (2002) suggested that routine administrative, bureaucratic, and organizational components of policing have the potential to be at least as stressful as some of the more low-frequency, high-danger encounters.

Several studies have found that officers identify administrative policies, lack of support, and inconsistent working schedules, as well as inadequate resources, times pressure, lack of communication, and work overload as major stressors (Biggam et al. 1997; Kroes et al. 1974). Moreover, Johnson et al. (2005) found that in addition to police officers, ambulance drivers and prison officers were identified as being the most stressful occupations in terms of both physical and psychological well-being, and had lower levels of job satisfaction, when compared with the other 26 occupations that were included in the study (e.g., nursing, teaching). Although research on the impact of OS arising from everyday stressors on officers clearly delineates negative consequences, this line of research currently remains scarce for first responders in general. Failing to acknowledge these factors may inadvertently underestimate the extent to which they can exacerbate stress-related traumatic reactions after critical incidents (Kleim and Westphal 2011). Furthermore, OS arising from routine stressors (vs. critical incidents) is predictive of psychological distress generally, and PTSD symptomatology specifically (Liberman et al. 2002), thereby underscoring the importance of addressing OS in first responders.

In addition to the well-documented link between OS and stress-related disorders, OS is putatively linked to another mental health indicator - anger (Fitzgerald et al. 2003). Persistent stress, such as that which is experienced by first responders by virtue of their occupation, has the potential to result in excessive anger (Leonard and Alison 1999). The psychological strain and stress experienced by first responders poses elevated risk for PTSD, which includes anger as a possible symptom (American Psychiatric Association 2013; APA) and is one of three symptoms that most affect quality of life in individuals with PTSD (Forbes et al. 2019). Notably, anger is sometimes symptomatic of depressive, anxiety, and substance use disorders (APA 2013), each of which are prevalent in first responder populations (Carleton et al. 2017). OS is also frequently associated with burnout (e.g., Brunetto et al. 2012; Kop et al. 1999), another syndrome that is related to elevated displays of anger (Maslach 2003), including in police officers (Jackson and Maslach 1982). Aside from being a symptom of a broader disorder, anger may too function independently as a maladaptive coping strategy for first responders. For instance, Burke (1998) found that in a sample of police officers, expressing anger may serve as "escapist coping" in the face of OS.
Clearly, first responders' occupations are tremendously stressful; however, little research has investigated how various dimensions of OS may differentially impact aspects of first responders' mental health. OS is a multidimensional construct reflecting various sources of chronic, routine stressors, thereby indicating that different elements of one's occupational climate can contribute to OS. Specifically, six dimensions of OS have been identified (Osipow 1998): (1) role overload (perceptions of unreasonable workload superseding available resources), (2) role insufficiency (perceiving poor fit between one's skills and their occupation), (3) role ambiguity (lack of clarity regarding job expectations and evaluative components), (4) role boundary (perceptions of supervisory demands being in conflict with smaller groups within the organization), (5) responsibility (perceptions of high levels of responsibility for work-related activities and performance), and (6) physical environment (exposure to unpleasant or unsafe physical working conditioning, such as excessive noise, heat, cold, etc.). OS thus arises from varied sources, suggesting that the cause of stress experienced may yield different consequences (Osipow 1998).

Evidence suggests that different dimensions of OS do indeed have differential effects on mental health (e.g., Demerouti et al. 2001; Mañas et al. 2018). Role overload reflects perceptions regarding workload; research indicates that excessive job demands (e.g., work overload) can lead to the development of burnout (Demerouti et al. 2001), including in police officers (Martinussen et al. 2007). Role insufficiency, which refers to perceptions of poor job fit, is thought to be associated with job satisfaction; that is, job dissatisfaction is ostensibly a function of experiencing an uncomfortable discrepancy between what one is capable of and aspires to, and one's perception of what the job actually entails or is able to offer (Locke 1969). According to Fitzgerald et al. (2003), the extent to which one experiences job satisfaction impacts one's vulnerability to anger. Role ambiguity is related to reduced productivity in the workplace (Mañas et al. 2018), and also fosters employees' doubt in their own performance and uncertainty with respect to potential consequences for failing to meet vague expectations (Rogalsky et al. 2016). Role ambiguity is also linked to unpleasant affective states in employees, including anxiety, depression, lack of self-confidence, and difficulty interacting socially (Lee and Ashforth 1996). According to Beck's (1999) expanded theory of depression, unjust treatment within interpersonal relationships, such as stress arising from conflicts with supervisors (i.e., role boundary), has the potential to lead to an anger response due to perceived environmental provocation. In general, occupational stressors that are psychosocial in nature appear to be most closely related to poor mental health 
(Niedhammer et al. 2020). Indeed, Niedhammer et al. (2020) have found that the physical environment of one's working conditions is not related to depression and, by extension, may also not be predictive of anger.

The experience and expression of anger in first responders is problematic and has physical and psychological consequences at the individual level, as well as organizational and societal consequences. In terms of physical health, anger is associated with increased risk for coronary heart disease and coronary artery disease (Caltabiano and Sarafino 2002), incidence of lung cancer (Kissen 1967), rheumatoid arthritis and hypertension (Cobb et al. 1969), and the development of PTSD (Spielberger 1999). Smith et al. (2005) found that occupational stress increased cardiovascular symptoms via anger. Recently, trait anger was found to be a significant predictor of physical health in police officers (Kale and Gedik 2020). Moreover, anger appears to play a moderating role between occupational stressors and employee productivity (Ilie et al. 2011). Anger resulting from OS also presents repercussions for interactions with the public, which is particularly problematic for those working as public service personnel (i.e., first responders). For instance, in a sample of police officers, Wilson et al. (2001) found that excessive use of force and poor citizen interactions are sometimes attributed to expressions of officers' levels of maladaptive anger. It is thus important to identify factors that might counteract anger in first responders and, specifically, factors that can explain the influence of OS on anger, thereby providing opportunities for intervention. Resiliency might be one such factor.

Resiliency is defined as one's ability to adapt to change, persist in the face of hardship, and employ adaptive coping strategies (Connor and Davidson 2003); resiliency to has been shown to attenuate the effect of OS on wellbeing (Reicherts and Pihet 2000). Resiliency is inversely related to stress vulnerability (Kobasa and Puccetti 1983; Lazarus 1993) and reflects the capacity to surmount shortterm or chronic stress without facing typical repercussions of resulting distress (Velichkovsky 2009). Resiliency is known to optimize job performance (Arnetz et al. 2008) and decrease the risk of burnout (Velichkovsky 2009). Research also suggests that increased resiliency is associated with decreased levels of both state and trait anger in a sample of law enforcement personnel (Wilson et al. 2001). Similarly, elevated resiliency has been associated with less intensive distress in a sample of police officers (Velichkovsky 2009).

There is, however, limited research on resiliency in first responders (Lanza et al. 2018), especially in terms of whether it functions as a mechanism by which OS does or does not result in negative mental health consequences. Protective factors that counteract the development of adverse mental health consequences include a greater sense of self-worth, adaptive social functioning across occupational, social leisure activities, and familial domains (i.e., better social adjustment) during police academy training (Yuan et al. 2011) and social support, with the latter being the most robust predictor for PTSD after traumatic events (Brewin et al. 2000; Ozer et al. 2003). Whether or not trait resiliency, conceptualized as an individual's predisposition and general ability to adapt to and withstand adversity (Bonanno 2008), functions as a similar protective factor against adverse mental health consequences generally, and maladaptive anger, specifically, is unclear.

The aim of the current study was first to examine the relationships between OS dimensions, anger, and resiliency in a diverse sample of first responders. Second, we sought to examine whether resiliency plays a mediating role in relations between OS dimensions and anger. Based on the previous literature, it was hypothesized that (1) OS dimensions would be significantly negatively related to resiliency and positively tied to anger, (2) that resiliency would be significantly negatively related to anger, and (3) that resiliency would mediate relations between OS dimensions and anger.

\section{Methods}

\section{Participants}

Participants were 201 first responders from the same municipality, including police officers, civilian law enforcement personnel (administrative and dispatch), firefighters, and police detention jailers. Most participants were male (77.6\%) with an average age of 43.73 years $(S D=10.97$, range $=20-66)$; the sample was mostly comprised of police officers (65.2\%), followed by firefighters (19.7\%), administrative law enforcement personnel (7.6\%), dispatch law enforcement personnel (7.1\%), and police detention jailers $(0.5 \%)$. On average, participants had been employed with the municipality for 15.14 years ( $S D=10$ years), with duration of years served spanning four months to 43 years. The majority of participants reported being married or common law with an intimate partner (79.4\%).

\section{Measures}

\section{Demographic Form}

An author-constructed questionnaire was used to obtain information from first responders about their age, gender, marital status, profession type, and duration of employment. 


\section{Occupational Stress Inventory-R-Occupational Role Questionnaire (ORQ; Osipow 1998)}

The ORQ is a 60 -item, 5-point $(1=$ rarely or never true; $5=$ true most of the time) Likert-type selfreport measure of occupational stress. Raw scores are converted to standardized $T$ scores, with higher scores indicating greater levels of occupational stress. The ORQ includes six subscales, each with 10 items, that reflect different sources of occupational stress: (1) role overload, (2) role insufficiency, (3) role ambiguity, (4) role boundary, (5) responsibility, and (6) physical environment. Role overload reflects occupational stress resulting from unreasonable workload that exceeds resources available. Role insufficiency refers to when the source of occupational is due to a poor fit between one's skills and their job. Role ambiguity describes occupational stress induced by lack of clarity in expectations related to one's employment. Role boundary refers to stress resulting from conflicting supervisory demands and factions within one's enterprise. The Responsibility subscale refers to stress resulting from substantial responsibility within one's organization and experiencing pressure from being frequently relied on. Finally, physical environment refers to the conditions of the physical work setting itself, including exposure to noise, dust, and poisonous substances, and may also encompass an erratic work schedule or feeling isolated. The ORQ has demonstrated good construct validity and internal consistency (Spokane and Ferrara 2001), the latter of which was acceptable to good in the current study depending on the subscale (see Table 1). Public safety norms were used in the current study for $T$-score conversion.

\section{DSM-5 Self-Rated Level 1 Cross-Cutting Symptom Measure- Anger subscale (DSM-5 Level 1; American Psychiatric Association 2013)}

The DSM-5 Level 1 is a 23 item self-report measure rated on a 5 -point Likert scale $(0=$ none or not at all, $4=$ severe or nearly every day), that assesses symptoms experienced by the respondent in 13 psychiatric domains (e.g., depression, anger, mania, anxiety) within the last 2 weeks. A rating of mild (i.e., 2) or greater within the anger domain signals the necessity of additional inquiry. Research supports the utility of using the DSM-5 Level 1 measure in both clinical and nonclinical samples (Bravo et al. 2018; Hurst and Kavanagh 2017). Test-retest reliabilities of the cross-cutting symptom items tend to be between good to excellent (Narrow et al. 2013). Internal consistency for the DSM-5 Level 1 measure was excellent in the present study ( $\alpha=0.93$ ).
Connor-Davidson Resilience Scale (CD-RISC, Connor and Davidson 2003)

The CD-RISC is a self-report measure of trait resilience comprised of 25 items measured on a 5-point Likert scale ( $1=$ not at all, $4=$ true nearly all of the time) with higher scores indicative of greater resilience. Total scores on the CD-RISC are computed to provide a global indication of trait resilience. The CD-RISC has been shown to reliably distinguish between those with higher and lower resilience, has good test-retest reliability and convergent validity (Connor and Davidson 2003), and internal consistency was excellent for the present study $(\alpha=0.95)$.

\section{Procedure}

Participants completed a psychological wellness survey including the ORQ, DSM-5 Level 1 measure, and CD-RISC for the purposes of informing the municipality's strategy for employee wellness. Participants were given general information regarding the survey and its goals during in-person survey information sessions by the research team and Human Resources representatives. During these sessions, participants were given an information sheet with instructions on how to complete the survey. Participants were notified that they were free to decline to participate without consequence within their respective occupations; explanation of confidentiality and anonymity was also given at this time. Following informed consent, participants completed the survey either via paper-and-pencil format, or a secure online platform, and data were merged into a confidential database.

\section{Results}

Pearson product moment correlations were conducted using a conservative alpha $(p=0.01)$ given multiple comparisons to test relations among ORQ subscales, DSM-5 Anger, and CD-RISC (see Table 1). As predicted, significant negative relations, ranging from weak to moderate in magnitude, emerged between all ORQ subscales (except for ORQ Physical Environment) and CD-RISC, and significant moderate positive relations were found between all ORQ subscales and DSM-5 Anger, again, except for ORQ Physical Environment. Additionally, DSM-5 Anger was significantly negatively correlated with CD-RISC, which was moderate in magnitude.

Six mediation analyses were conducted using Hayes' (2013) Process v3 macro, with ORQ subscales as predictor variables, CD-RISC as the mediator, and DSM-5 Anger as the criterion variable; all analyses were employed using 10,000 bootstrap 


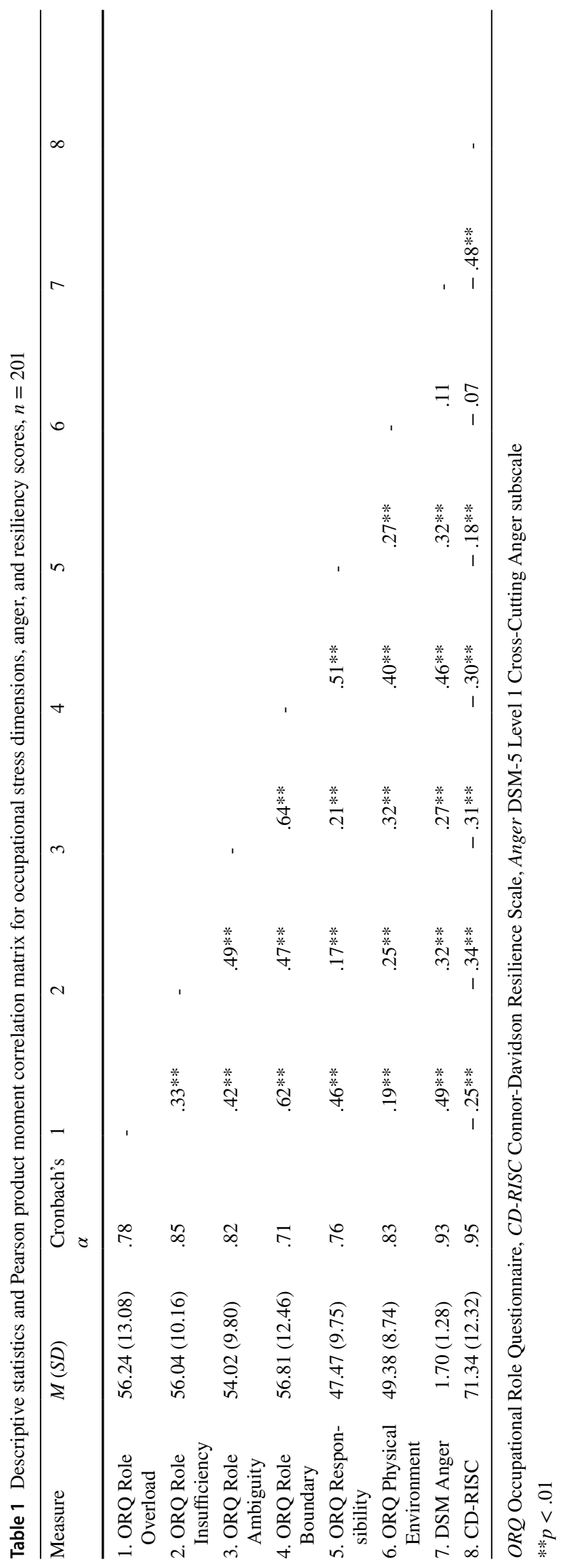


Table 2 Effect of occupational stress dimensions on anger through resiliency, $n=201$

\begin{tabular}{|c|c|c|c|c|c|c|c|}
\hline \multirow[t]{2}{*}{ Predictor $(X)$} & \multirow[t]{2}{*}{ Mediator $(M)$} & \multirow[t]{2}{*}{ Criterion $(Y)$} & \multirow[b]{2}{*}{ Model $R^{2}$} & \multirow[t]{2}{*}{ Total effect ( $c^{\prime}$ path) } & \multirow[t]{2}{*}{ Direct effect ( $c$ path) } & \multicolumn{2}{|c|}{ Indirect effect ( $a b$ path) } \\
\hline & & & & & & $P E(S E)$ & $\mathrm{BC} 95 \% \mathrm{CI}$ \\
\hline ORQ Role Overload & CD-RISC & Anger & $.25 * *$ & $0.05(0.01)^{* * *}$ & $0.04(0.01) * * *$ & $0.01(0.01)^{* * *}$ & $(0.00-0.013)$ \\
\hline ORQ Role Insufficiency & CD-RISC & Anger & $.09 * *$ & $0.03(0.01)^{* *}$ & $0.02(0.01)^{*}$ & $0.01(0.00)^{* *}$ & $(0.01-0.02)$ \\
\hline ORQ Role Ambiguity & CD-RISC & Anger & $.07 * * *$ & $0.03(0.01)^{* * *}$ & $0.02(0.01)$ & $0.01(0.00)^{* * *}$ & $(0.01-0.02)$ \\
\hline ORQ Role Boundary & CD-RISC & Anger & $.21 * * *$ & $0.05(0.01)^{* * *}$ & $0.04(0.01)^{* * *}$ & $0.01(0.00)^{* * *}$ & $(0.00-0.01)$ \\
\hline ORQ Responsibility & CD-RISC & Anger & $.29 * * *$ & $0.05(0.01)^{*}$ & $0.04(0.01)^{* * *}$ & $0.01(0.00)^{*}$ & $(0.00-0.01)$ \\
\hline $\begin{array}{l}\text { ORQ Physical Environ- } \\
\text { ment }\end{array}$ & CD-RISC & Anger & .02 & $0.02(0.01)$ & $0.01(0.01)$ & $0.00(0.01)$ & $(-0.01-0.02)$ \\
\hline
\end{tabular}

Mediation analyses conducted using $k=10,000$

ORQ Occupational Role Questionnaire, CD-RISCConnor-Davidson Resilience Scale, AngerDSM-5 Level 1 Cross-Cutting Anger subscale $* p<.05 ; * p<.01 ; * * p<.001$

samples (see Table 2). Mediation implies that the effect of a predictor variable on an outcome variable is best explained by a mediator variable, which is itself both caused by the predictor, and causes the outcome variable, indicating that the casual relationship between predictor and outcome variables is indirect. Full mediation is said to occur when the inclusion of the mediator reduces the relationship between the independent variable and the dependent variable. Results indicated that the effect of ORQ Role Overload on DSM-5 Anger was significantly mediated by CD-RISC, with the overall model accounting for $25 \%$ of the variance in DSM-5 Anger scores. The effect of ORQ Role Insufficiency was also significantly mediated by CD-RISC, with the overall model accounting for $9 \%$ of the variance in the criterion. The effect ORQ Role Ambiguity on DSM-5 Anger was significantly mediated by CD-RISC, which accounted for $7 \%$ of the variance. The indirect effect of CD-RISC on the relationship between ORQ Role Boundary and DSM-5 Anger was more potent, with the overall model accounting for $21 \%$ of the variance. Similarly, the effect of ORQ Responsibility on DSM-5 Anger was significantly mediated CD-RISC, with the overall model accounting for $29 \%$ of the variance in DSM-5 Anger scores.

\section{Discussion}

The purpose of the present study was to examine the effects of various dimensions of OS (i.e., role ambiguity, role insufficiency, role overload, role boundary, responsibility, and physical environment) on levels of maladaptive anger in first responders and to determine whether trait resiliency has the ability to mediate relations between OS and anger. To date, resiliency has yet to be considered as a potential explanatory variable in the relationship between OS and anger in first responder populations. OS scores in the current sample were higher relative to normative samples (Pasca and Wagner 2012), while resiliency levels were comparably lower than the general population (Connor and Davidson 2003). The severity of anger that first responders reported experiencing within the two works prior to completing the survey was nearly twice the size of that which has been reported in college samples (Bravo et al. 2018). Thus, our findings suggest that first responders experience higher levels of OS, are comparably less resilient, and experience greater anger, relative to normative samples.

In support of our hypotheses, all OS dimensions, except for OS elicited by first responders' physical working environment, were significantly positively related to anger and significantly negatively to resiliency. Furthermore, resiliency was able to mediate relations between all OS dimensions and anger, except for the physical environment stress dimension. Specifically, results from mediation analyses ostensibly indicate that the relationship between OS dimensions, anger, and resiliency varies in terms of potency, suggesting that OS dimensions are differentially influenced by resiliency. Thus, resiliency may function as a protective factor more effectively against some sources of OS than others.

The OS dimension wherein resiliency appears to figure most prominently in its influence on anger was the responsibility dimension (resiliency accounting for $29 \%$ of variance in scores). This dimension reflects OS arising from an individuals' perception of the level of responsibility for work performance of their subordinates and, consequently, might result in poor co-worker relationships (Osipow 1998). Research indicates that perceived social support promotes mental health among first responders (see Prati and Pietrantoni 2010). As such, poor relationships with, and a resulting lack of social support from, coworkers as a result of endorsing the responsibility dimension may make robust dispositional resiliency particularly important as a protective factor against OS. It is unsurprising that the responsibility dimension emerged as a potent predictor of anger levels. First responders hold a distinctive amount of responsibility 
by virtue of their employment, both to their coworkers and the general public. Thus, being an emotion that is commonly elicited in response to perceived injustice (Leach 2008), first responders may react with anger to perceptions of coworkers as failing to uphold their due diligence within their role as a first responder.

The role overload OS dimension followed in terms of the potency of the effect of resiliency in accounting for role overload's relationship with anger (resiliency accounting for $25 \%$ of variance in scores). Role overload refers to when OS arises when an individual perceives their workload as unreasonable given the available resources (Osipow 1998). Previous research has putatively linked crime scene investigators' utilization of anger in coping with the effect of perceptions of work overload (Sollie et al. 2017), which may again reflect a response to perceived injustice. High dispositional resiliency might be particularly important in this relationship by allowing one to draw on internal resources to assuage stress when external resources are insufficient in managing the work at hand. Furthermore, Mazzola et al. (2011) have found that resiliency mitigates the negative effect of demanding of work situations, which conceivably, and in accordance with the current findings, appears to hold with first responders.

Role boundary refers to when individuals feel assailed by conflicting supervisory demands and responsibilities. Previous research indicates that anger tends to be experienced in response to supervisors' transgression of what can be realistically expected from employees (Mawritz et al. 2014). Our findings suggest that this relationship persists in first responder population but presents the possibility that dispositional resiliency (resiliency accounting for $21 \%$ of variance in scores) may serve to reduce responding with anger when experiencing difficulty in supervisory relationships.

The effect of resiliency was comparably reduced for the relationship between role insufficiency and anger (accounting for 9\% of variance in scores). Role insufficiency refers to one's perception of there being a poor fit between their skills and their occupation and may result in feelings of incompetency (Osipow 1998). This dimension has previously been negatively associated with job satisfaction, whereas resiliency is positively related to job satisfaction (Karami et al. 2017); thus, the current findings with our sample of first responders remain consistent with previous research. Perhaps, the potency of resiliency's effect on the relationship between role insufficiency and anger is less so than the previous OS dimensions given that role insufficiency stress tends to emerge from incompetency issues (Osipow 1998). Resiliency tends to be a protective factor against perceived injustice (Irizarry et al. 2016) and perceptions of injustice elicit anger (Leach 2008). Thus, whereas the relationship between previously discussed OS dimensions and anger could be more so about perceived injustice, role insufficiency may reflect internal discomfort and uncertainty about competency.

Similarly, role ambiguity refers to uncertainty regarding work-related expectations (Osipow 1998); therefore, resiliency's comparably reduced effect on the relationship between role ambiguity and anger (vs. responsibility; role overload; role boundary) may again be due to internal discomfort as opposed to perceived injustice. That notwithstanding, previous research suggests that developing resiliency strategies can mitigate the negative impact of role ambiguity on work performance (De Clercq 2019); this finding is perhaps applicable to the impact of role ambiguity on expressions of anger in first responders.

Finally, resiliency did not account for the relationship between the physical environment OS dimension and anger. Research indicates that psychosocial occupational stressors are the most commonly related to mental health issues (Niedhammer et al. 2020); thus, finding that OS pertaining to first responders' physical work environment was not associated with excessive anger is unsurprising. Thus, taken together, findings from the current study suggest that the effect of resiliency on the relationship between OS dimensions and anger is most robust when the source of stress is psychosocial in nature and encompasses an element of perceived injustice.

Findings from the current study have several important implications. First, the current study helps to generalize much of the available research on occupational stress, anger, and resiliency to first responders specifically and aids in identifying which dimensions of OS predict anger. Importantly, the current findings indicate that dispositional resiliency can indeed explain the relationship between OS dimensions and anger, and also provide an indication of specific types of dimensions that might be most amenable to resiliency's influence, and common underlying themes among those dimensions (i.e., psychosocial; related to perceived injustice). It is conceivable that repercussions of OS-induced anger could be mitigated by adopting a resiliency-focused training.

Resiliency-promotion paradigms have been found to be effective in several domains; for instance, Arnetz et al. (2008) have found that implementing such paradigms may improve well-being, promote stress resiliency, and optimize job performance in a sample of police officers. Additionally, Lanza et al. (2018) have advocated for enhancing resiliency in first responders via self-care workshops for prevention, postvention, and treatment for occupation-related stress and trauma. Notably, there is limited research on resiliency in first responders; thus, Lanza et al.'s (2018) argument was predicated on inferring information from existing findings on the benefits of self-compassion (Germer and Neff 2013) and self-care for professional work (APA, 2002). Sollie et al. (2017) also argue 
for the implementation of resiliency-enhancing strategies for crime scene investigators in light of their frequently distressing work situations. More recent research has found that disaster (vs. first) responses who engaged in self-care practices were able to foster self-compassion, which ostensibly has the ability to foster resiliency competencies (Roysircar et al. 2020); it is possible that these findings hold for first responders, as well. Findings from the current study suggest that fostering resiliency in first responders could be particularly helpful in reducing the effects of perceiving unreasonable amounts of responsibility and workload, and experiencing supervisory boundary transgressions on anger. In doing so, personal and organizational repercussions of anger in first responders could be reduced as a result of responders' increased ability to access and utilize psychological and physical resources (Paton et al. 2009).

Despite being a meaningful contribution to the literature on OS, anger, and resiliency in first responders, findings from the current study must be considered in light of certain limitations and avenues for future research. First, we were unable to conduct analyses differentially by employment role, which precludes our ability to determine the extent to which our findings figure prominently across all forms of first responder groups. As it stands, Kleim and Westphal (2011) have discussed that first responders face unique mental health consequences and have unique needs based on their employment type (e.g., firefighters, police, volunteers, etc.); thus, any form of resiliency-promoting intervention may need to be specific to employment type (Lanza et al. 2018). Despite a relatively small sample size, however, the current study was able to detect several significant mediating effects. Replication is nonetheless needed to investigate, confirm, and extend these findings. Second, data from the current study are cross-sectional, which precludes any inferences of causation in the direction we assume the relationship to exist. Third, the current study used self-report measures, which are subject to certain biases, including social desirability. Fourth, participants in the current study were recruited from a single municipality; it is possible that other municipalities might produce discrepant results. Indeed, current participants scored remarkably high on measures of OS, which might have informed departmental awareness for the need to develop a wellness program; thereby, suggesting that our participants might be substantially different from those recruited from other municipalities. Finally, resiliency was assessed as a unidimensional, dispositional construct. Future research should investigate whether various, more dynamic forms of resiliency are particularly helpful with specific forms of OS. For instance, whether self-compassion or social support conceptualized as resiliency factors (Papazoglou et al., 2019) are particularly beneficial in addressing the effects of specific OS dimensions would be integral to formulating an effective and tailored resiliency-promotion paradigm.
Notwithstanding its limitations, the present research depicts the importance of examining resiliency and its potential to buffer specific aspects of OS, thereby promoting mental wellness and reducing anger-related consequences at work broadly for first responders. Results from the present study underscore how first responders' subjective experience of OS, and the sources of that stress, can predict anger. Furthermore, these results highlight the importance of addressing the effect of OS on anger as a function of first responders' capacities for resiliency, thereby providing prospective avenues to enhance responders' mental health and mitigate ramifications of OS-induced anger.

Data Availability Datasets generated during and/or analyzed during the current study are available from the corresponding author on reasonable request.

\section{Declarations}

Ethics Approval Research presented in the manuscript was conducted in accordance with the ethical guidelines put forth by the Canadian and American Psychological Association. Institutional review board approval was granted by the University of New Brunswick Research Ethics Board (REB 026-2019). All applicable international, national, and/or institutional guidelines for the care and use of animals were followed. The current research was also performed in accordance with the ethical standards as laid down in the 1964 Declaration of Helsinki and its later amendments or comparable ethical standards.

Consent to Participate Informed consent was obtained from all individual participants included in the study.

Conflict of Interest The authors declare that they have no conflict of interest.

\section{References}

American Psychiatric Association (2013) Diagnostic and statistical manual of mental disorders (5th ed.) Washington, DC

American Psychological Association (2002) Ethical principles of psychologists and code of conduct. Washington, DC

Beck AT (1999) Prisoners of hate: the cognitive basis of anger, hostility, and violence. Harper Collins, New York

Arnetz BB, Nevesal DC, Lumley MA, Backman L, Lublin A (2008) Trauma resilience training for police: psychophysiological and performance effects. J Police Crim Psychol 24(1):1-9. https://doi. org/10.1007/s11896-008-9030-y

Benedek DM, Fullerton C, Ursano RJ (2007) First responders: mental health consequences of natural and human-made disasters for public health and public safety workers. Annu Rev Public Health 28:55-68. https://doi.org/10.1146/annurev.publhealth.28. 021406.144037

Biggam FH, Power KG, Macdonald RR, Carcary WB, Moodie E (1997) Self-perceived occupational stress and distress in a Scottish police force. Work Stress 11(2):118-133. https://doi.org/10.1080/ 02678379708256829

Bonanno GA (2008) Loss, trauma, and human resilience: have we underestimated the human capacity to thrive after extremely 
aversive events? Psychol Trauma Theory Res Pract Policy S(1):101-113. https://doi.org/10.1037/1942-9681.S.1.101

Bravo AJ, Villarosa-Hurlocker MC, Pearson MR (2018) College student mental health: an evaluation of the DSM-5 self-rated Level 1 cross-cutting symptom measure. Psychol Assess 30(10):1382-1389. https://doi.org/10.1037/pas0000628

Brewin CR, Andrews B, Valentine JD (2000) Meta-analysis of risk factors for posttraumatic stress disorder in trauma-exposed adults. J Consult Clin Psychol 68(5):748-766. https://doi. org/10.1037/0022-006x68.5.748

Brown J, Fielding J, Grover J (1999) Distinguishing traumatic, vicarious and routine operational stressor exposure and attendant adverse consequences in a sample of police officers. Work \& Stress: An International Journal of Work, Health \& Organisations 13(4):312-325. https://doi.org/10.1080/02678379950019770

Brunetto Y, Teo ST, Shacklock, k., \& Farr-wharton, R. (2012) Emotional intelligence, job satisfaction, well-being and engagement: explaining organizational commitment and turnover intentions in policing. Hum Resour Manag J 22(4):428-441. https://doi.org/ 10.1111/1.1748-8583.2012.00198.x

Burke R (1998) Work and non-work stressors and well being among police officers: the role of coping. Anxiety Stress Coping 11:345362. https://doi.org/10.1080/10615809808248319

Caltabiano ML, Sarafino EP (2002) Health psychology: biosocial interactions, an Australian perspective. John Wiley \& Sons Australia, Brisbane

Carleton RN, Afifi TO, Turner S, Taillieu T, Duranceau S, Lebouthillier DM, Sareen J, Ricciardelli R, MacPhee RS, Groll D, Hozempa K, Brunet A, Weekes JR, Griffiths CT, Abrams KJ, Jones NA, Beshai S, Cramm HA, Dobson KS, Hatcher S, Keane TM, Stewart SH, Asmundson GJG (2017) Mental disorder symptoms among public safety personnel in Canada. Can J Psychiatry 63(1):54-64. https:// doi.org/10.1177/0706743717723825

Cobb S, Hunt P, Harburg E (1969) The intrafamilial transmission of rheumatoid arthritis II: an interview measure of rheumatoid arthritis. J Chronic Dis 22(4):203-215. https://doi. org/10.1016/0021-9681(69)90014-9

Connor KM, Davidson JR (2003) Development of a new resilience scale: the Connor-Davidson Resilience Scale (CD-RISC). Depress Anxiety 18(2):76-82. https://doi.org/10.1002/da.10113

Daas-Brailsford P (2010) Secondary trauma among disaster responders. In: Daas-Brailsford P (ed) Crisis and disaster counseling. SAGE, Thousand Oaks, CA, pp 213-228

De Clercq D (2019) Getting creative with resources: how resilience, task interdependence, and emotion sharing mitigate the damage of employee role ambiguity. J Appl Behav Sci 55(3):369-391. https:// doi.org/10.1177/0021886319853803

Demerouti E, Bakker AB, Nachreiner F, Schaufeli WB (2001) The job-demands model of burnout. J Appl Psychol 86(3):499-512. https://doi.org/10.1037/0021-9010.86.3.499

Figley CR (1995) Compassion fatigue: toward a new understanding of the costs of caring. In: Stamm NB (ed) Secondary traumatic stress: Self-care issues for clinicians, researchers, and educators, 2nd edn. Sidran, Lutherville, MD, pp 3-28

Fitzgerald ST, Haythornthwaite JA, Suchday S, Ewart CK (2003) Anger in young Black and White workers: effects of job control, dissatisfaction, and support. J Behav Med 26(4):283-296. https:// doi.org/10.1023/A:1024228026022

Forbes D, Pedlar D, Adler AB, Bennett C, Bryant R, Busuttil W, Cooper J, Creamer MC, Fear NT, Greenberg N, Heber A, Hinton M, Hopewood M, Jetly R, Lawrence-Wood E, McFarlane A, Metcalf O, O'Donnell M, Phelps A, Richardson JD, Sadler N, Schnurr PP, Sharp M, Thompson JM, Ursano RJ, Van Hoof M, Wade D, Wessely S (2019) Treatment of military-related post-traumatic stress disorder: challenges, innovations, and the way forward. Int Rev Psychiatry 31(1):950-110. https://doi. org/10.1080/09540261.2019.1595545

Fridell LA, Binder A (1992) Police officer decision making in potentially violent confrontations. J Crim Just 20(5):385-399. https://doi.org/10.1016/0047-2352(92)90075-k

Germer CK, Neff KD (2013) Self-compassion in clinical practice. J Clin Psychol 69:856-867. https://doi.org/10.1002/jclp.22021

Holloway, H. C., \& Fullerton, C. S. (1994) The psychology of terror and its aftermath. In R. J. Ursano, R. J. McCaughey, \& C. S. Fullerton (Eds.), Individual and community responses to trauma and disaster: The structure of human chaos (pp. 31-45). Cambridge University Press

Hurst JE, Kavanagh PS (2017) Life history strategies and psychopathology: the faster the life strategies, the more symptoms of psychopathology. Evol Hum Behav 38(1):1-8. https://doi. org/10.1016/j.evolhumbehav.2016.06.001

Ilie A, Penney LM, Ispas D, Iliescu D (2011) The role of trait anger in the relationship between stressors and counterproductive work behaviors: convergent findings from multiple studies and methodologies. Appl Psychol 61(3):415-436. https://doi.org/10. 1111/j.1464-0597.2011.00476.x

Irizarry C, Marlowe JM, Hallahan L, Bull M (2016) Restoring connections: social workers' practice wisdom towards achieving social justice. Br J Soc Work 46(7):1855-1871. https://doi. org/10.1093/bjsw/bcv129

Jackson SE, Maslach C (1982) After-effects of job-related stress: families as victims. J Organ Behav 3(1):63-77. https://doi.org/10.1002/ job.4030030106

Johnson S, Cooper C, Cartwright S, Donald I, Taylor P, Millet C (2005) The experience of work-related stress across occupations. J Manag Psychol 20(2):178-187. https://doi.org/10.1108/ 02683940510579803

Kale A, Gedik Z (2020) Quality of life in riot police: links to anger, emotion regulation, depression, and anxiety. Appl Res Qual Life 15(1):107-125. https://doi.org/10.1007/s11482-018-9667-3

Karami J, Moradi A, Hatamian P (2017) The effect of resilience, self-efficacy, and social support on job satisfaction among the employed, middle-aged and elderly. Iranian Journal of Ageing 12(3):300-311

Kessler RC, Berglund P, Demler O, Jin R, Koretz D, Merikangas KR, Rush JA, Walters EE, Wang PS (2003) The epidemiology of major depression. Results from the National Comorbidity Survey replication. J Am Med Assoc 289(23):3095-3105. https://doi. org/10.1001/jama.289.23.3095

Kessler RC, Chin WT, Demler O, Merikangas KR, Walters EE (2005) Prevalence, severity, and comorbidity of 12-month DSM-IV disorders in the National Comorbidity Survey Replication. Arch Gen Psychiatry 62(6):617-627. https://doi.org/10.1001/archpsyc.62.6.617

Kissen DM (1967) Psychosocial factors, personality and lung cancer in men aged 55-64. Br J Med Psychol 40(1):29-44. https://doi. org/10.1111/j.2044-8341.1967.tb00553.x

Kleim B, Westphal M (2011) Mental health in first responders: a review and recommendation for prevention and intervention strategies. Traumatology 17(4):17-24. https://doi. org/10.1177/1534765611429079

Kobasa SC, Puccetti MC (1983) Personality and social resources in stress resistance. J Pers Soc Psychol 45(4):839-850. https://doi. org/10.1037/0022-3514.45.4.839

Kop N, Euwema MC, Schaufeli. (1999) Burnout, job stress and violent behavior among Dutch police officers. Work Stress 13(4):326340. https://doi.org/10.1080/02678379950019789

Kroes WH, Margolis B, Hurrell JJ (1974) Job stress in policemen. J Police Sci Adm 2(2):145-155

Lanza A, Roysircar G, Rodgers A (2018) First responder mental healthcare: evidence based prevention, postvention, and treatment. 
Prof Psychol Res Pract 49(3):193-204. https://doi.org/10.1037/ pro0000192

Lazarus RS (1993) From psychological stress to the emotions: a history of changing outlooks. Annu Rev Psychol 44(1):1-22. https://doi. org/10.1146/annurev.ps.44.020193.000245

Leach, CW (2008). Envy, inferiority, and injustice: three bases of anger about inequality. In R. H. Smith (Eds.), Envy: theory and research (pp. 94-116). Oxford University Press. https://doi.org/10.1093/ acprof:oso/9780195327953.003.0006

Lee RT, Ashforth BE (1996) A meta-analytic examination of the correlates of the three dimensions of job burnout. J Appl Psychol 81(2):123-133. https://doi.org/10.1037/0021-9010.81.2.123

Leonard R, Alison L (1999) Critical incident stress debriefing and its effects on coping strategies and anger in a sample of Australian police officers involved in shooting incidents. Work Stress 13(2):144-161. https://doi.org/10.1080/026783799296110

Liberman A, Best SR, Metzler TJ, Fagan J (2002) Routine occupational stress and psychological distress in police. Policing: An International Journal Police Strategies and Management 25(2):421-441. https://doi.org/10.1108/13639510210429446

Locke EA (1969) What is job satisfaction? Organ Behav Hum Perform 4(4):309-336. https://doi.org/10.1016/0030-5073(69)90013-0

Ozer EJ, Best SR, Lipsey TL, Weiss DS (2003) Predictors of posttraumatic stress disorder and symptoms in adults: a meta-analysis. Psychol Bull 129(1):52-57. https://doi.org/10.1037/1942-9681.S.1.3

Pasca R, Wagner SL (2012) Occupational stress, mental health and satisfaction in the Canadian multicultural workplace. Soc Indic Res 109(3):377-393. https://doi.org/10.1007/s11205-011-9907-5

Mañas MA, Díaz-Fúnez P, Pecino V, López-Liria R, Padilla D, AguilarParra JM (2018) Consequences of team job demands: role ambiguity climate, affective engagement, and extra-role performance. Front Psychol 8:2292. https://doi.org/10.3389/fpsyg.2017.02292

Martinussen M, Richardsen A, Burke R (2007) Job demands, job resources, and burnout among police officers. J Crim Just 35(3):239-249. https://doi.org/10.1016/j.jcrimjus.2007.03.001

Mawritz MB, Folger R, Latham GP (2014) Supervisors' exceedingly difficult goals and abusive supervision. The mediating effects of hindrance stress, anger, and anxiety. J Organ Behav 35(3):358372. https://doi.org/10.1002/job.1879

Maslach C (2003) Job burnout: new directions in research intervention. Curr Dir Psychol Sci 12(5):189-192. https://doi. org/10.1111/1467-8721.01258

Mazzola JJ, Schonfeld IS, Spector PE (2011) What qualitative research has taught us about occupational stress. Stress and Health: Journal of the International Society for the Investigation of Stress 27(2):93-110. https://doi.org/10.1002/smi.1386

Narrow WE, Clarke DE, Kuramoto SJ, Kraemer HC, Kupfer DJ, Greiner L, Regier DA (2013) DSM-5 field trials in the United States and Canada, part III: development and reliability testing of a cross-cutting symptom assessment for DSM-5. American Journal of Psychiatric 170(1):71-82. https://doi.org/10.1176/appi. ajp.2012.12071000

Niedhammer I, Coindre K, Memmi S, Bertrais S, Chastang J (2020) Working conditions and depression in the French national working population: results from the SUMER study. J Psychiatr Res 123:178-186. https://doi.org/10.1016/j.jpsychires.2020.01.003

Osipow SH (1998) Occupational stress inventory—revised edition (OSI-R): professional manual. Psychological Assessment Resources Inc, USA

Papazoglou, K., Russo, C., \& Johnson, O. (2019). Police self-compassion. In L. Galiana \& N. Sanso (Eds.), The power of compassion. (pp. 285-296). Nova Science Publishers
Paton D, Violanti J, Burke K, Gherke A (2009) Traumatic stress in police officers: a career length assessment from recruitment to retirement. Thomas Publisher Ltd, Charles. C

Prati G, Pietrantoni L (2010) The relation of perceived and received social support to mental health among firster responders: a metaanalytic review. J Community Psychol 38(3):403-417. https://doi. org/10.1002/jcop.20371

Reicherts M, Pihet S (2000) Job newcomers coping with stressful situations: a micro analysis of adequate coping and well-being. Swiss J Psychol 59(4):303-316. https://doi. org/10.1024//1421-0185.59.4.303

Rogalsky K, Doherty A, Paradis KF (2016) Understanding the sport event volunteer experience: an investigation of role ambiguity and its correlates. J Sport Manag 20:453-469. https://doi.org/10.1123/ jsm.2015-0214

Roysircar G, Lanza AM, Macedonia MF (2020). Disaster responder self-care, self-compassion, and protective factors: a pilot study on responders' resilience and competence. In C. A. Bowers, D. C. Beidel, \& M. R. Marks (Eds.), Mental Health Intervention and Treatment of First Responders and Emergency Workers (pp. 169189). IGI Global. https://doi.org/10.4018/978-1-5225-9803-9.ch010

Smith LA, Roman A, Dollard MF, Winefield AH, Siegrist J (2005) Effort-reward imbalance at work: the effects of work stress on anger and cardiovascular disease symptoms in a community sample. Stress Health 21(2):113-128. https://doi.org/10.1002/smi.1045

Sollie H, Kop N, Euwema MC (2017) Mental resilience of crime scene investigators: how police officers perceive and cope with the impact of demanding work situations. Crim Justice Behav 44(12):1580-1603. https://doi.org/10.1177/0093854817716959

Spielberger, C. D. (1999). STAXI-2: State-Trait Anger Expression Inventory-2: professional manual. Psychological Assessment Resources

Spokane, A. R., \& Ferrara, D. (2001). Samuel S. Osipow's contributions to occupational mental health and the assessment of stress: the occupational stress inventory. In F Leong \& A. Barak (Eds.), Contemporary models in vocational psychology: A volume in honor of Samuel H. Osipow (pp. 79-96). Taylor \& Francis Group

Stanley IH, Hom MA, Joiner TE (2016) A systematic review of suicidal thoughts and behaviors among police officers, firefighters, EMTs, and paramedics. Clin Psychol Rev 44:25-44. https://doi. org/10.1016/j.cpr.2016.12.002

van der Velden PG, Rademaker AR, Vermetten E (2013) Police officers: a high-risk group for the development of mental health disturbances? A cohort study. BMJ Open 3(1):e001720. https:// doi.org/10.1136/bmjopen-2012-001720

Velichkovsky BM (2009). Primary and secondary appraisals in measuring resilience. Psychology in Russia: State of the Art, 5(1), 539-563. https://doi.org/10.11621/pir.2009.0027

Wilson SA, Tinker RH, Becker LA, Logan CR (2001) Stress management with law enforcement personnel: a controlled outcome study of EMDR versus a traditional stress management program. Int J Stress Manag 8:179-200. https://doi. org/10.1023/A:1011366408693

Yuan C, Wang Z, Inslicht S, McCaslin S, Metzler TJ, Henn-Haase C, Apfel BA, Tong H, Neylan TC, Marmar C (2011) Protective factors for posttraumatic stress disorder symptoms in a prospective study of police officers. Psychiatry Res 188(1):45-50. https://doi. org/10.1016/j.psychres.2010.10.034

Publisher's Note Springer Nature remains neutral with regard to jurisdictional claims in published maps and institutional affiliations. 